\title{
A New Aluminum Pot Line Rectiformer Scheme with Effective Harmonic Suppression Capability
}

\author{
Mahmood Al-Mahari ${ }^{1}$, S. Ali Al-Mawsawi ${ }^{2}$ Fadhel Albasri $^{3}$ \\ ${ }^{1}$ Aluminum Bahrain (ALBA), Bahrain \\ ${ }^{2,3}$ Department of Electrical and Electronics Engineering, University of Bahrain, Bahrain
}

\begin{tabular}{l} 
Article Info \\
\hline Article history: \\
Received Jul 9, 2018 \\
Revised Sep 3, 2018 \\
Accepted Sep 10, 2018 \\
\hline
\end{tabular}

Keyword:

Metals industry

Rectifiers

Power system harmonics

Power quality

Harmonic analysis

\begin{abstract}
The conversion from alternating current to direct current creates harmonics and causes power quality issues especially when large amount of power being converted. To mitigate these issues, conventional schemes for pot line Rectiformers are integrated with passive harmonic filters (PHF), which are either connected directly to the feeding grid or connected to each tertiary winding of the Rectiformer regulating transformer. This paper presents a new pot line Rectiformer scheme that reduces the distortion at the Rectiformer terminal and has better harmonic attenuation capability at the point of common coupling (PCC) by using parallel delta connected (PDC) tertiary winding between two adjacent Rectiformers. The proposed pot line scheme is modeled and simulated using MATLAB/Simulink. A comparison is made with Aluminum Bahrain (ALBA) new 900MW pot line 6 (PL6) scheme in terms of harmonic elimination, capability, operational constrains and cost/space requirements.
\end{abstract}

Copyright $(2) 2018$ Institute of Advanced Engineering and Science. All rights reserved.

\section{Corresponding Author:}

Fadhel A. Albasri,

Department of Electrical and Electronics Engineering,

University of Bahrain,

P.O. Box 32038, Bahrain.

Email: falbasri@uob.edu.bh

\section{INTRODUCTION}

Aluminum Smelter is basically a series of connected electrolytic cells (Pots) supplied by direct current electrical equipment known as Rectiformer. The Rectiformer is a combination of rectifier coupled to a transformer which is used in Aluminum smelters to supply the pot line with direct current. Aluminum Bahrain (ALBA) company consumes more than 1.6GW DC power to feed their five pot lines. Conventional pot line scheme is consisting of six Rectiformers connected in parallel and each is phase shifted in order to achieve 72 pulse system which effectively reduces the harmonic currents at PCC [1]. The ideal characteristic harmonic orders penetrating into the network in this case will be [2]-[3]:

$$
h=72 n \pm 1(n=1,2,3 \ldots)
$$

However, this scheme is not sufficient to keep the distortions below the recommended standard acceptable limits [4]. PHF which is connected directly to the feeding grid is mostly employed to attenuate the harmonic distortions and to provide reactive power compensation [5]-[9]. The existing harmonics in the electrical network that can be obtained by measurement or computer simulation will decide the tuning frequencies of the PHF.

Another alternative scheme in which the harmonic filter is connected to the regulating transformer tertiary winding of each Rectiformer unit has been employed [10]-[12]. Reference [10] discussed the most economical method to maintain the voltage THD within $2 \%$ which is achieved by connecting the PHF to the 
regulating transformer tertiary winding. PHF connected to tertiary winding scheme is also discussed in reference [11]. Connecting the PHF to the tertiary winding reduces the harmonic effects by creating low impedance path for harmonic to flow and achieves the customer commercial goals by reducing the reactive power demand which will result an optimized sizing of equipments such as power cables. The new scheme for ALBA PL6 Rectiformer units is based on PHF connected to the regulating transformer tertiary winding as shown in Figure 1. This configuration was considered to satisfy the IEEE 519 recommended distortion limits. Same scheme has been already implemented in Ma'aden (Saudi Arabian Mining Company) [12]. This scheme will not prevent the harmonics from flowing in the regulating transformer when the PHF is not connected.

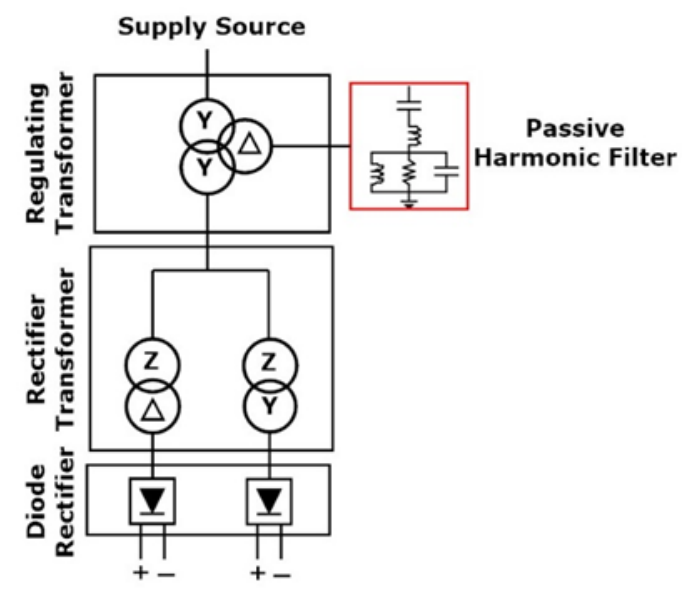

Figure 1. Rectiformer unit with PHF connected to tertiary winding

In this paper, a new scheme is proposed and compared with ALBA PL6 scheme in terms of harmonic attenuation capability, operational constrains, cost and space requirements. It also opens a domain for new ideas for optimizing the PHF design [13]. MATLAB/SIMULINK environment is used to evaluate the performance of both schemes.

\section{ALUMINUM SMELTER RECTIFORMER}

In aluminum smelters, diode base rectifiers are mostly used rather than thyristor base rectifier. The main reason behind the usage of diode base unit is that it can work manually in case of emergencies even when controls fail and has better performance in terms of power quality [14]. In general, the Rectiformer unit shown in Figure 2 and Figure 3 consist of [15]-[17]:
a. Regulating Transformer
b. Rectifier Transformer
c. Rectifier
d. Cooling system
e. Local control equipment

In general, for unit power less than 120MVA, the regulating transformer can be located in the same tank as shown in Figure 2. However, for higher rating, it can be located in separate tanks as shown in Figure 3. 


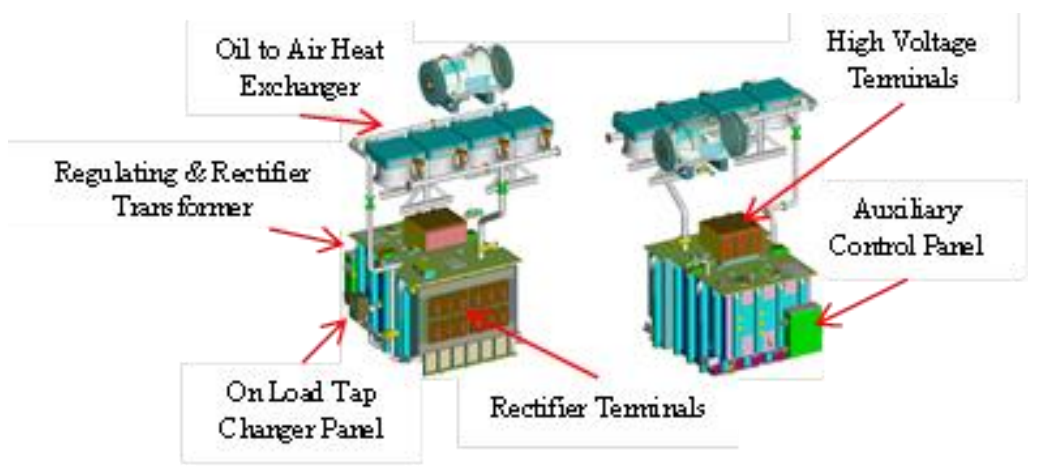

Figure 2. Rectiformer unit with regulating and rectifier transformer in the same tank

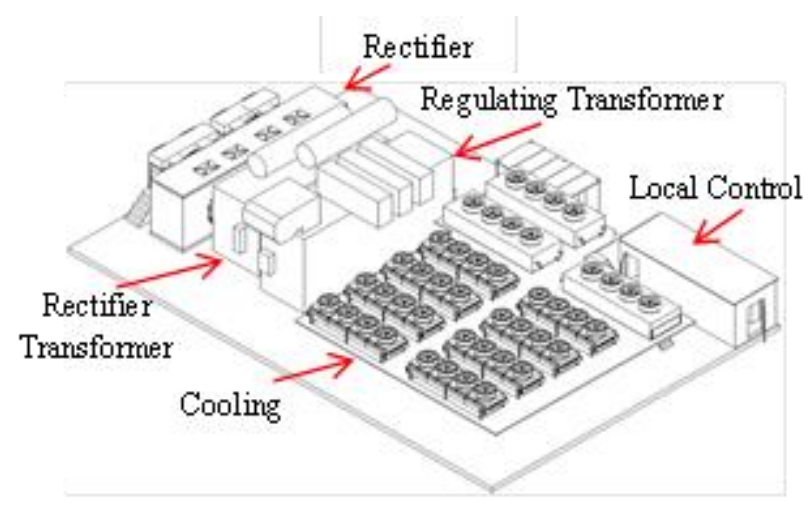

Figure 3. Rectiformer unit with regulating and rectifier transformers in separate tanks

\subsection{Regulating Transformer}

The regulating transformer is fitted with on-load tap changer for the regulation range of the secondary voltage by stepping the regulation transformer on load tap changer upwards or downwards depending on the voltage set value.

\subsection{Rectifier Transformer}

The rectifier transformer with two secondary windings, both connected to a separate three phase bridge rectifier in order to get twelve pulse output. For a complete pot line Rectiformers, the primary of the rectifier transformer is phase shifted in order to achieve 72 pulses for six units connected in parallel scheme. The saturable reactors installed in the rectifier transformer are used for fine current control between on-load tap changer step by acting like a variable impedance to the rectifier input. The feature of the saturable reactor are discussed in [18]. The saturable reactors are not considered in the simulation because the results evaluation has been don at steady state in which the reactor characteristic is not varying.

\subsection{Rectifier}

The 12 pulse diode rectifier is constituted by two "Graetz', bridges connected in parallel and housed in a sealed shelter to prevent the entrance of dust, sand and other contaminations. The rectifier diodes and fuses are cooled by deionized water circulating through the aluminum extruded profile. The main functions of the cooling system are cooling the rectifier frames and cooling of the air in the rectifier container.

\subsection{Cooling Equipment}

The cooling equipment is provided with oil to air heat exchangers installed remote from the transformer as shown in Figure 3 or on the top of it as shown in Figure 2. Most designers are maintaining one redundant heat exchanger bank or at least one redundant fan for each bank. 


\subsection{Local Control}

The local control could be housed in a control building or near to the unit itself depending on the design. The local control is equipped with all necessary apparatus for local rectifier control, metering and protection. The rectifier is controlled by a programmable logic controller (PLC) to do rectifier operation, fast current regulation and rectifier protection. Auxiliaries low voltage supply is also controlled by the local control equipment.

\section{PROPOSED PARALLEL DELTA CONNECTION SCHEME (PDC)}

Figure 4 shows the proposed scheme of 24 pulse system. Two Rectiformers with their regulating transformer delta connected tertiary winding is connected in parallel for harmonic filtering. This scheme was proposed for HVDC system, the wiring and tertiary winding design has been evaluated in reference [19]. Similar approach also presented in [20] where harmonics at specific order trapped by shunt connected transformer. This technique can be used also for higher harmonic orders. The reactive power compensator and the tuned passive filters are connected to the parallel links as shown in Figure 4. In this case, it is assumed that the load is pure DC and by using square wave analysis as presented in [19]-[21], the current passing into the regulating transformer secondary of unit 1 and 2 can be expressed as:

$$
\begin{aligned}
& I_{1}=\frac{4 \sqrt{3}}{\pi}\left[\cos \omega t-\frac{1}{11} \cos 11 \omega t+\frac{1}{13} \cos 13 \omega t-\frac{1}{23} \cos 23 \omega t+\frac{1}{25} \cos 25 \omega t-\cdots\right] \\
& I_{2}=\frac{4 \sqrt{3}}{\pi}\left[\cos \omega t+\frac{1}{11} \cos 11 \omega t-\frac{1}{13} \cos 13 \omega t-\frac{1}{23} \cos 23 \omega t+\frac{1}{25} \cos 25 \omega t-\cdots\right]
\end{aligned}
$$

The currents passing in the tertiary windings of unit 1 and 2 respectively expressed as:

$$
\begin{aligned}
& I_{12}=\frac{4 \sqrt{3}}{\pi}\left[k_{1} \cos \left(\omega t+\frac{\pi}{6}\right)-\left\{-\frac{k_{11}}{11} \cos \left(11 \omega t-\frac{\pi}{6}\right)+\frac{k_{13}}{13} \cos \left(13 \omega t+\frac{\pi}{6}\right)-\frac{k_{23}}{23} \cos \left(23 \omega t-\frac{\pi}{6}\right)+\right.\right. \\
& \left.\left.\frac{k_{25}}{25} \cos \left(25 \omega t+\frac{\pi}{6}\right)-\cdots\right\}\right] \\
& I_{22}=\frac{4 \sqrt{3}}{\pi}\left[k_{1} \cos \left(\omega t+\frac{\pi}{6}\right)-\left\{\frac{k_{11}}{11} \cos \left(11 \omega t-\frac{\pi}{6}\right)-\frac{k_{13}}{13} \cos \left(13 \omega t+\frac{\pi}{6}\right)-\frac{k_{23}}{23} \cos \left(23 \omega t-\frac{\pi}{6}\right)+\right.\right. \\
& \left.\left.\frac{k_{25}}{25} \cos \left(25 \omega t+\frac{\pi}{6}\right)-\cdots\right\}\right]
\end{aligned}
$$

The current passing in the parallel link is obtained by adding (3) and (4), which yields to:

$$
I_{3}=I_{12}+I_{22}=\frac{8 \sqrt{3}}{\pi}\left[k_{1} \cos \left(\omega t+\frac{\pi}{6}\right)+\frac{k_{23}}{23} \cos \left(23 \omega t-\frac{\pi}{6}\right)-\frac{k_{25}}{25} \cos \left(25 \omega t+\frac{\pi}{6}\right)-\cdots\right]
$$

In the proceeding equations, the coefficients $\mathrm{ki}(\mathrm{i}=1,2,3, \ldots)$ can be approximated to unity as discussed by [9]:

$$
K_{12 n \pm 1} \approx 1
$$

Therefore, equation (5) can be simplified as:

$$
I_{3}=\left[k_{1} \cos \left(\omega t+\frac{\pi}{6}\right)+\frac{1}{23} \cos \left(23 \omega t-\frac{\pi}{6}\right)-\frac{1}{25} \cos \left(25 \omega t+\frac{\pi}{6}\right)-\cdots\right]
$$




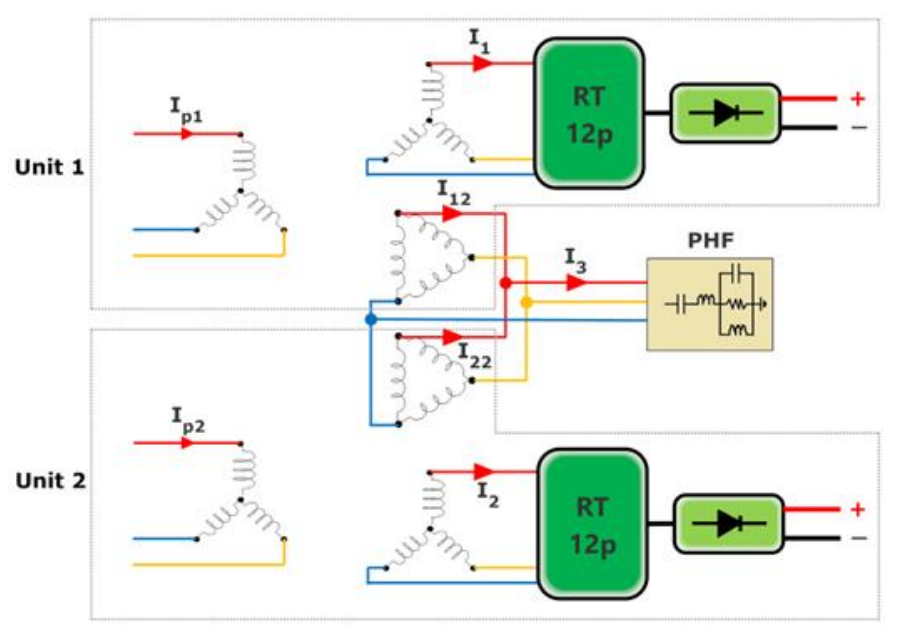

Figure 4. PDC scheme of 24 pulse system

According to (8), the parallel links connecting the tertiary delta windings can eliminate the harmonics of order $12 n \pm 1(n=1,3,5 \ldots)$ which flow out of the tertiary delta windings. Therefore, the harmonic filter shall be tuned to target the $24 n \pm 1$ orders. Without the PHF connected, the harmonics of order $24 n \pm 1$ $(\mathrm{n}=1,2,3 \ldots)$ will be presented in $\left(\mathrm{I}_{\mathrm{P} 1}\right)$ and $\left(\mathrm{I}_{\mathrm{P} 2}\right)$, which means that the dominant characteristic harmonics of the 12-pulse unit $\left(11^{\text {th }}\right.$ and $\left.13^{\text {th }}\right)$ will not flow into the regulating transformer even when the PHF is not connected.

\section{MATLAB SIMULINK SIMULATIONS}

\subsection{PDC Model}

The PDC scheme is simulated using the MATLAB/SIMULINK environment. The simulation modelling of the PDC scheme is presented in Figure 5. The electrical parameters of the simulated system are provided in Table 1, which is obtained from the actual proposed data for ALBA PL6 units. It is important that the phase shift between the two unit is equal to [22]:

$$
\text { Phase shift }=\frac{60}{\text { Number of converters }}=\frac{360^{\circ}}{\text { Number of pulses }}=15^{\circ}
$$

where, the number of converters is 4 and the number of pulses is 24 .

Table 1. Electrical Parameter of the System

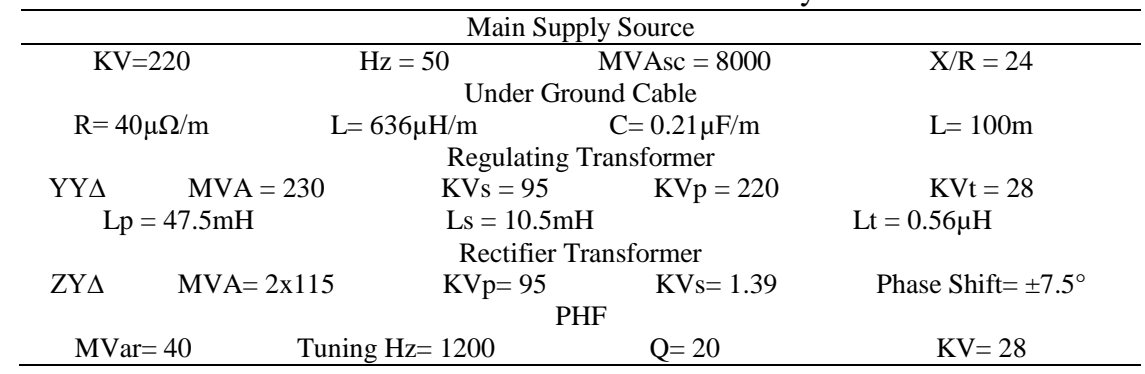




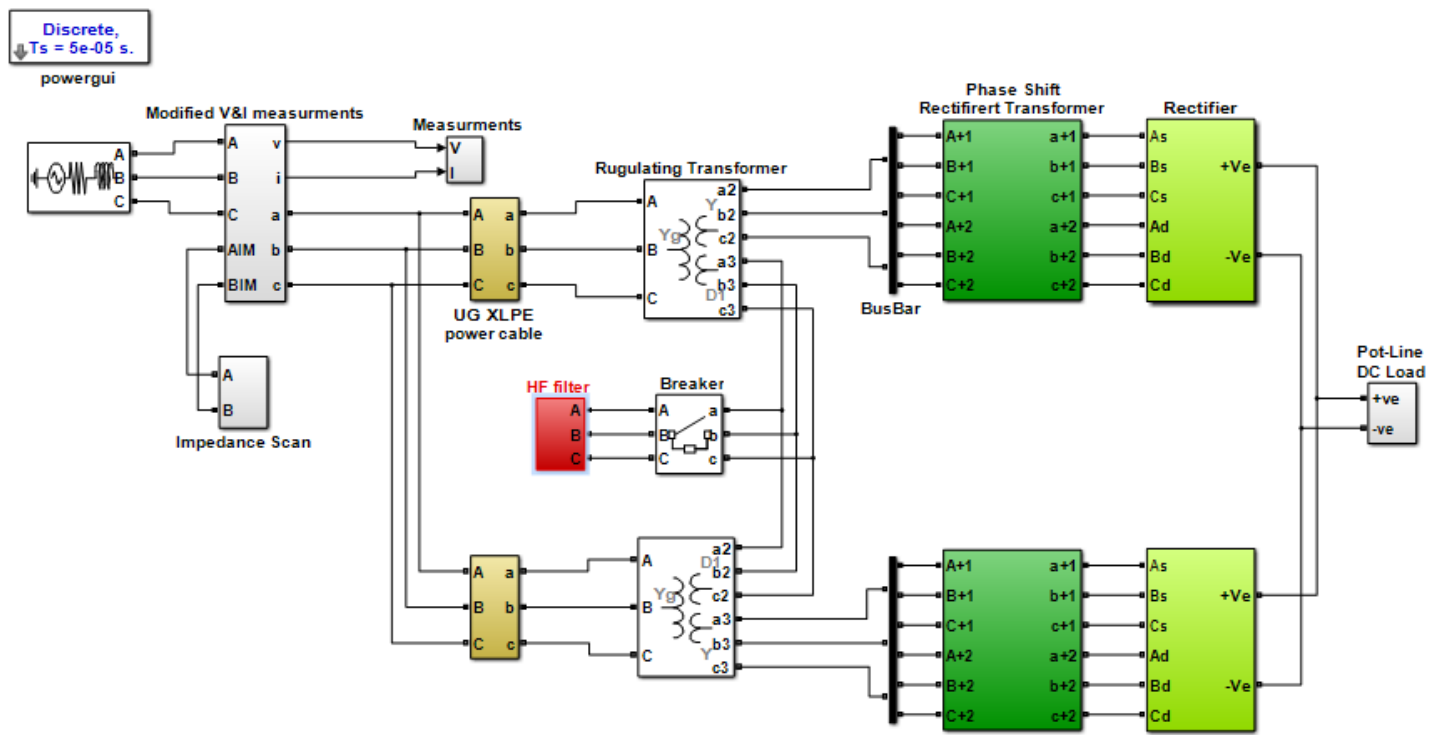

Figure 5. MATLAB SIMULINK model of PDC 24 pulse system

\subsection{PDC Scheme Simulation Results}

Figure 6 shows the simulation result of phase A primary current of unit $1\left(I_{P 1}\right)$ while the parallel link left open circuited. In this case, the current THD is 5.7\% due to the presence of characteristic harmonics $12 n \pm 1(n=1,2,3 \ldots)$. Figure 7 shows the same current with parallel link closed. In this case, the current THD reduced to $0.78 \%$ because the harmonics of order $12 n \pm 1 \quad(n=1,3,5 \ldots)$ have been eliminated. The Phase A current of the parallel link shown in Figure 8, is basically carrying the harmonics order of $12 n \pm 1(n=1,3,5 \ldots)$ as described in (6). With the PHF tuned as per (8) and connected as shown in Figure 5 to target the $23^{\text {rd }}$ and $25^{\text {th }}$ harmonic orders, phase A primary current of unit 1 is almost free from harmonics with THD equal to $0.06 \%$ as shown in Figure 9. Furthermore, it can be clearly seen from Figure 10 that PHF phase A current $\left(I_{3}\right)$ is carrying harmonics of order $23^{\text {rd }}$ and $25^{\text {th }}$ as discussed in (8).
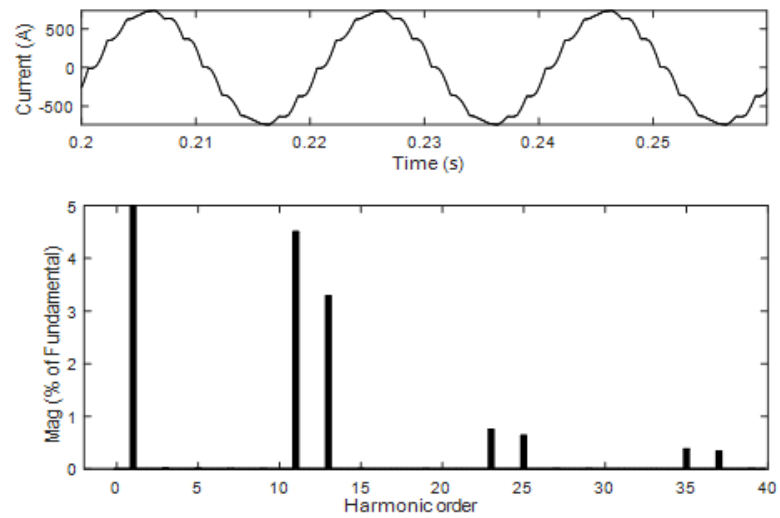

Figure 6. Phase A primary current of unit 1 with parallel link open
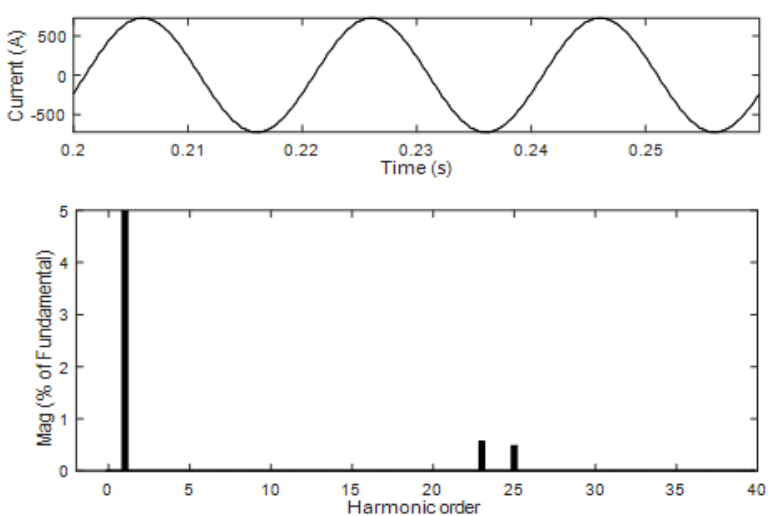

Figure 7. Phase A primary current of unit 1 with parallel link close 

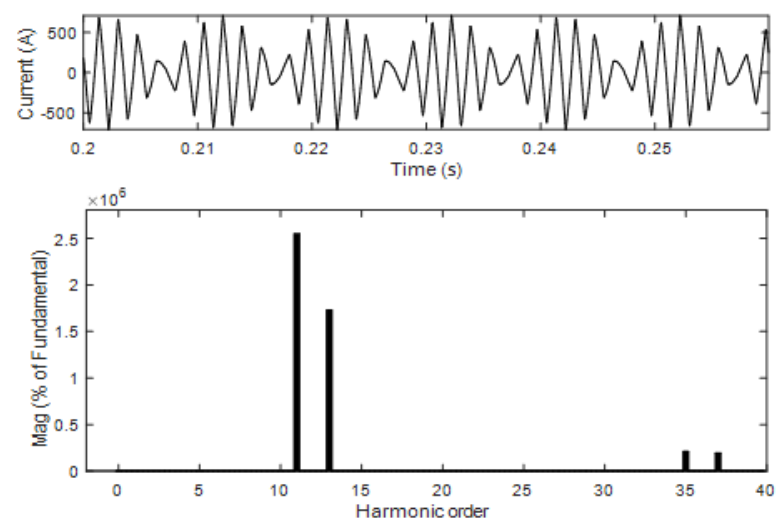

Figure 8. Phase A parallel link current
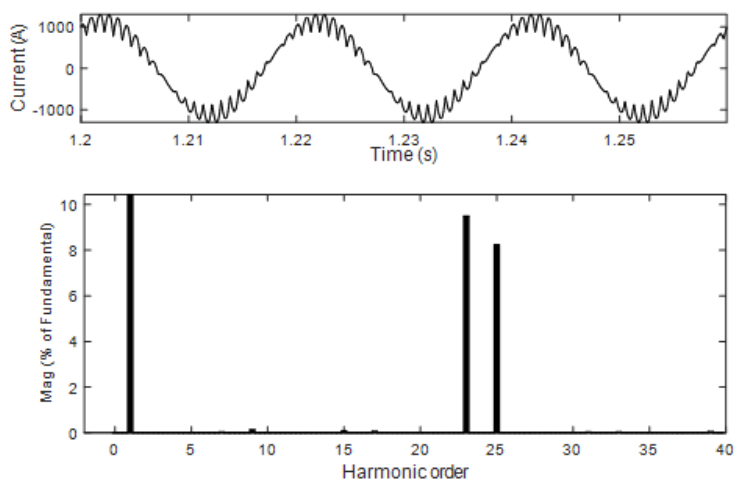

Figure 10. Phase A PHF current
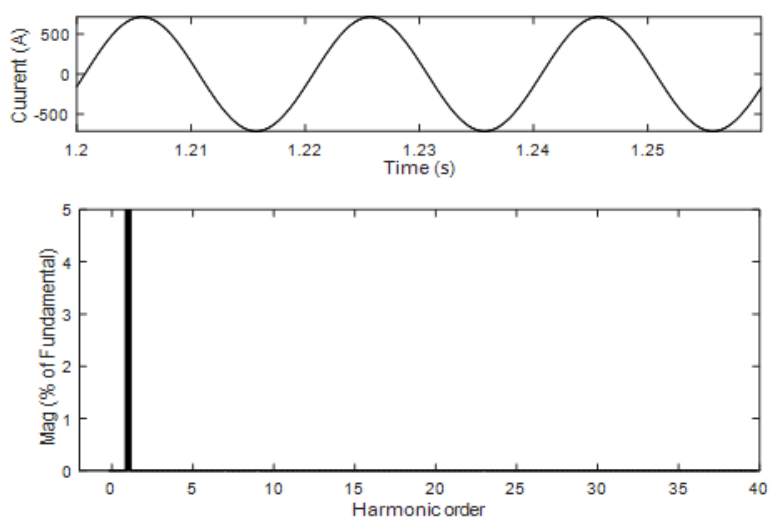

Figure 9. Phase A primary current to unit 1 with PHF connected
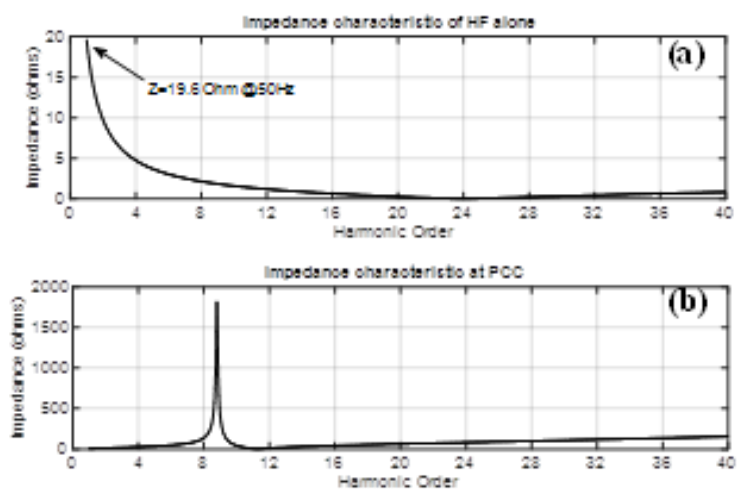

Figure 11. Impedance characteristic. (a) PHF impedance characteristic, (b) impedance characteristic at PCC

The reactive power supplied by the PHF can be checked by applying the impedance characteristic to the PHF while it is not connected to the system. The impedance characteristic of the PHF alone is shown in Figure 11(a). The reactive power at the fundamental frequency is equal to:

$$
\operatorname{Mvar}=\frac{\mathrm{V}^{2}}{\mathrm{Z}}=\frac{(28 \mathrm{k})^{2}}{19.6}=40
$$

Parallel resonant can be observed at PCC due to source impedance and other apparatus in the system as shown in Figure 11(b). This is one of the drawback of using PHF. However, resonance will not cause harmonics amplification in the study system because the generated harmonics orders dose not align with the peak of the impedance characteristic of the system.

\subsection{Performance Comparison}

In this section, a comparison between ALBA PL6 and the proposed PDC scheme is presented. Figure 12(a) shows the scheme of ALBA PL6, where the PHF is connected to the tertiary winding for reactive power compensation and for harmonic attenuation. The PHF parameters are extracted from the proposed data which are provided by the supplier. The PHF tuned to eliminate the 3rd, 5th, 7th and 11th order with total reactive power compensation of 240Mvar. The PDC scheme is shown in Figure 12(b). The PHF tuned at 5th, 12th and 24th with same reactive power compensation capability. Since ALBA PL6 is designed for N-2 operation, the performances of both schemes are evaluated at three operating conditions with PHF and without PHF. The rectifier transformer no load voltage output is assumed to have $0.3 \%$ voltage unbalance as this unbalance is always there in practice [23]. The parameters used in both models are shown in Table 1. The Rectiformer phase shift arrangement in the PDC scheme must be connected as shown in 
Figure $12(b)$ in order to eliminate the $12 n \pm 1(n=1,3,5 \ldots)$ harmonic. The results summary is shown in Figure 13 in percentage.

It can be clearly seen from Figure 13 that at all the tested scenarios, the performance of the proposed PDC scheme is superior over that of the ALBA PL6 scheme in terms of harmonic attenuation capability. The unit current TDD in PDC scheme is lower than ALBA PL6 scheme by more than 5\% when all units are in service.

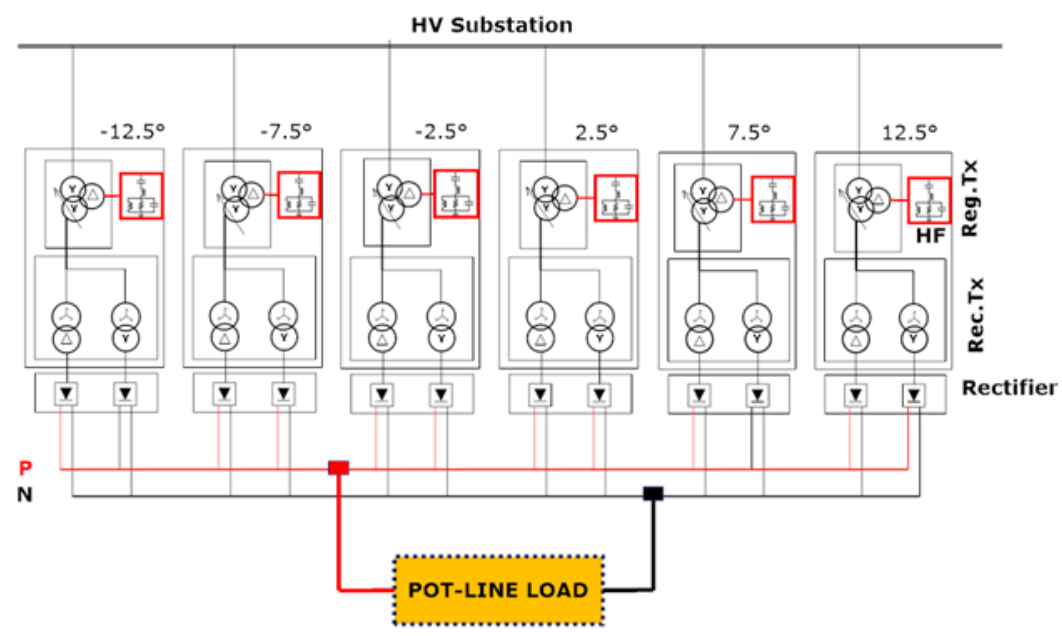

(a) ALBA PL6 Scheme

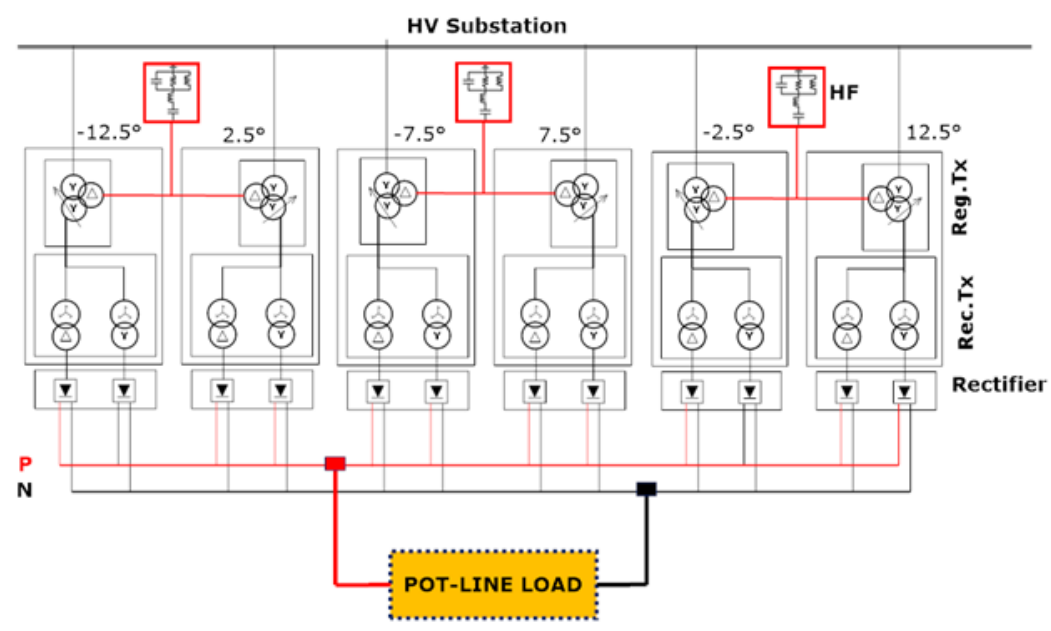

(b) The proposed pot line Rectiformer Scheme

Figure 12. Aluminum pot line Rectiformers of ALBA PL6 and the proposed Schemes 


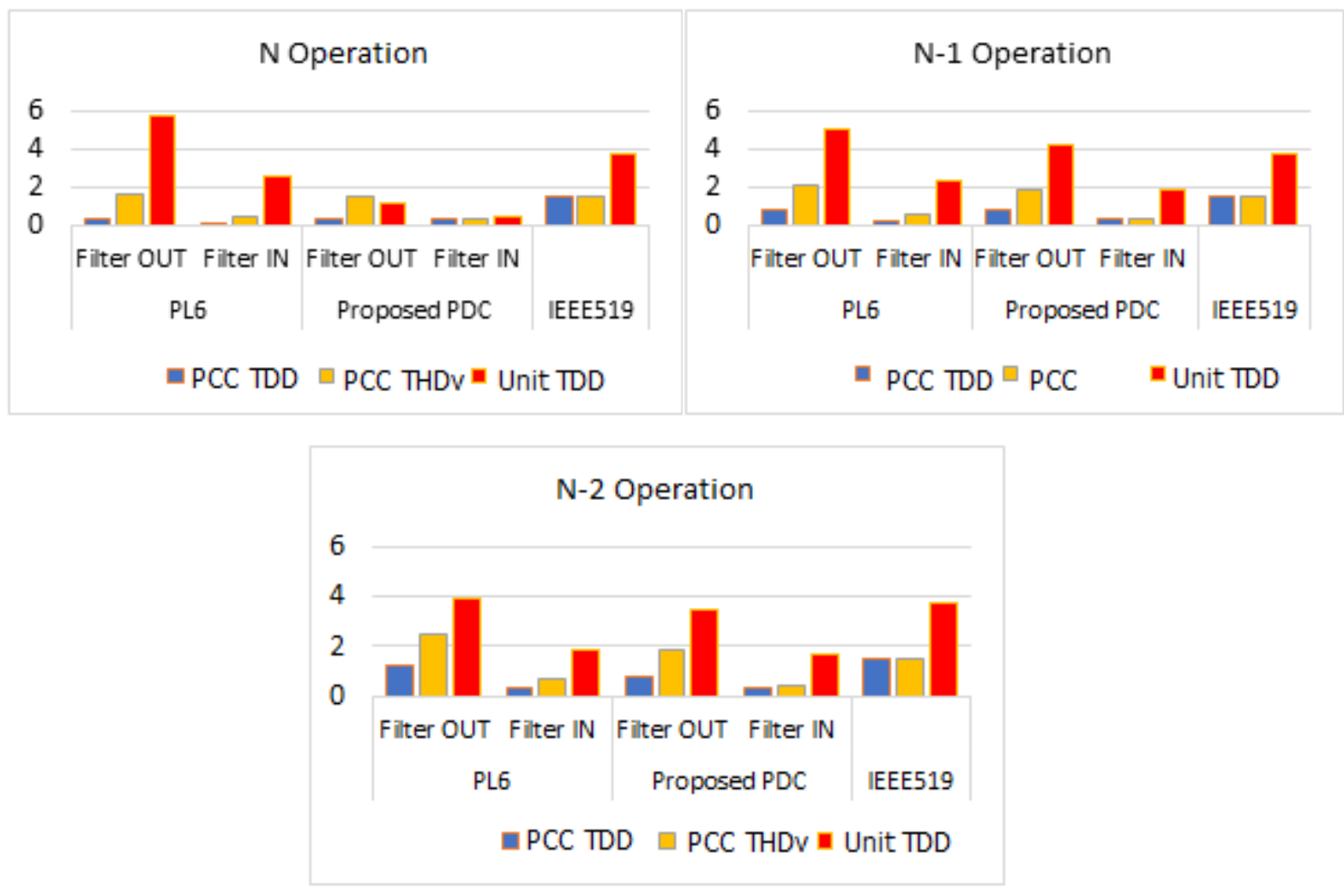

Figure 13. Summary of the simulation results

\subsection{Discussion}

\subsubsection{Harmonics Attenuation Capability}

From the obtained results, it can be seen that the proposed scheme can decrease the overall harmonic distortion, especially in the regulating transformers. On the other hand, ALBA PL6 scheme will not prevent the characteristic harmonics from flowing into the regulating transformer. Looking at the three operating scenarios, the PDC performance is better in attenuating the overall harmonic distortions as compared to ALBA PL6 scheme by improving the harmonic suppression performance which leads to better power quality.

\subsubsection{Practical Consideration}

In the proposed scheme, there will be six outages per year for the Recrtiformers and three for the block filters. It is reasonable to expect some 12 days per year to do maintenance for each Rectiformer and 3 days per year for each block filter which means that the potline is will not run under normal operating condition (Rectiformer is out or Block filter is out) for $23 \%$ of year and the potline will run under normal operating condition (All Recrtiformers and Block filters are in service) for $77 \%$ of the year. Based on the proposed potline scheme, the maintenance of the block filters shall be done before or after all the maintenance activities are completed on the Rectiformer units. This is required to ensure minimum distortion by maintaining the parallel link closed on each block.

During the $77 \%$ of the year, the $12^{\text {th }}$ order branch filter is not required because of the parallel links which effectively eliminate the $11^{\text {th }}$ and $13^{\text {th }}$ order harmonics. However, this branch is required to be in service when one Rectiformer unit form the same block is taken out of service as well as to support the reactive power requirements.

\subsubsection{Cost and Space}

In the proposed scheme, the number of the PHF is three as compared to ALBA PL6 scheme which require six. Consequently, the space requirements will reduce. However, the number of required breakers for the filter units is increased in the proposed scheme. The cost of the three PHF units as compared to six circuit breakers shall be evaluated by the owner. The maintenance and spare parts requirements for the PHF is relatively higher than circuit breakers. Indoor type switchgear is reliable with minimal maintenance requirements. Table 2 summarize the comparison between the conventional, ALBA PL6 and the proposed 
pot line scheme. In the conventional scheme, the PHF is directly connected to the high voltage feeding bus.

Table 2. Summery Comparison between Conventional, ABA PL6 and PDC Scheme

\begin{tabular}{lccc}
\hline \multicolumn{1}{c}{ Criteria } & Conventional & PL6 & PDC \\
\hline Harmonic Attenuation & $*$ & $* *$ & $* * *$ \\
Operational Flexibility & $* * *$ & $* *$ & $* *$ \\
Cost & $* * *$ & $* *$ & $* *$ \\
Space & $* *$ & $*$ & $* * *$ \\
Number of PHF Units & $* * *$ & $*$ & $* *$ \\
\hline
\end{tabular}

\section{CONCLUSION}

A proposed PDC scheme of 24-pulse system has been successfully modeled and simulated in MATLAB/SIMULINK environment. The performance of the scheme is evaluated by showing the harmonic contents of unit 1, parallel link and PHF currents. The parallel link has effectively trapped the targeted harmonic orders which has reduced the THD in the primary current of the regulating transformer to less than $1 \%$. In addition, the proposed aluminum pot line Rectiformer scheme shows high capability of reducing the overall distortion levels at PCC as well as at each unit terminal at $\mathrm{N}$ operating condition which represent almost $80 \%$ of the year. Comparison of the proposed scheme with conventional, and ALBA PL6 has been discussed in terms of harmonic attenuation capability, operation flexibility, cost and space requirements. Only half of the number of the PHF is required in the proposed PDC scheme as compared to the ALBA PL6 scheme. Tuning the PHF to target $11^{\text {th }}$ and $13^{\text {th }}$ harmonic order is not required in the proposed scheme when it is running under $\mathrm{N}$ operating condition due to the presence of the parallel links between adjacent Rectiformer units.

\section{ACKNOWLEDGEMENTS}

The authors would like to thank Aluminum Bahrain (ALBA) for their support in this research work and for providing the required actual system data.

\section{REFERENCES}

[1] D. Venkatasubramanian and S. P. Natarajan, "Analysis of Harmonics and Ripple Current in Multi-module Converters with Increasing Number of Modules for High Power Applications," International Journal of Power Electronics and Drive System (IJPEDS), vol/issue: 7(4), pp. 1402-1409, 2016.

[2] M. Zhiheng, et al., "Harmonic analysis and simulation of multi-pulse rectifiers applied in electrolysis industry," IEEE Industry Applications Society Annual Meeting, 2014.

[3] Rajesh T. and Nirmalkumar A., "A Shunt Active Power Filter for 12 Pulse Converter Using Source Current Detection Approach," International Journal of Power Electronics and Drive System (IJPEDS), vol/issue: 7(1), pp. 225-234, 2016.

[4] H. K. Thakkar, et al., "Harmonics in industrial power networks of aluminium smelters - A comprehensive mitigation approach," International Journal of Smart Grid and Clean Energy, vol/issue: 4(1), 2015.

[5] N. Gersch, "Investigation into the harmonic behavior of multipulse converter systems in an aluminium smelter," University of Wollongong, Boyne Smelters Limited, Queensland. Power quality center, 2000.

[6] P. Pollock and C. Duffey, "Power quality and corrective action in an aluminum smelter," Petroleum and Chemical Industry conference, Industry Applications Society 45th Annual. IEEE. Paper No. PCIC-98-20, 1998.

[7] M. Ermis, et al., "Power Quality Solutions for 12-Pulse Smelter Converters in ETI Aluminum Works," IEEE transactions on industry applications, vol/issue: 40(6), 2004

[8] A. T. Yokoyama, et al., "Investigation and mitigation of the amplification of the harmonic current to filtering system of an aluminum smelter," Proceedings of the 6th WSEAS International Conference on Power Systems, Lisbon, Portugal, 2006.

[9] R. D. M. Soomro, et al., "Power Quality Improvement in QUCEST Larkana Campus by using Three Types of Power Filters," International Journal of Power Electronics and Drive System (IJPEDS), vol/issue: 8(4), pp. 1876$1885,2017$.

[10] M. Wiestner, et al., "Power quality results in energy efficient aluminium smelter," $A B B$ Switzerland, $A B B$ Technical publication, 2010.

[11] Z. Y. Zhao, et al., "Operational characteristics of a filtering rectifier transformer for industrial power systems," Turkish Journal of Electrical Engineering \& Computer Sciences, 2013.

[12] A. Collier, et al., "Workhorses of industry - Industrial transformers in a DC environment," ABB Technical publication, 2012.

[13] X. Li, et al., "Damped High Passive Filter-A New Filtering Scheme for Multipulse Rectifier Systems," IEEE Transactions on Power Delivery, vol/issue: 32(1), 2017 
[14] S. K. Jhajharia, "A comparative study of diode and thyristor converters used in the aluminum smelters," International Journal of Electrical Engineering and Technology (IJEET), vol/issue: 4(6), pp. 01-13, 2013.

[15] A. Siebert, et al., "AC to DC Power Conversion Now and in the Future," IEEE transactions on industry applications, vol/issue: 38(4), 2002.

[16] A. Agalgaonkar, et al., "Open loop response characterisation of an aluminium smelting plant for short time interval feeding," IEEE Conference Publications, Power \& Energy Society General Meeting, 2009.

[17] Areva T\&D, "Special Transformer," Power Transformer, first edition. Paris La defense, France, Areva T\&D, 2008.

[18] H. Jiang, et al., "Frequency control by aluminum smelter load response in an isolated wind power system: A study for an industrial case," IEEE Power and Energy Society General Meeting (PES), 2013.

[19] C. Liang, et al., "Harmonic Elimination Using Parallel Connected Filtering Windings for Converter Transformers in HVDC Systems," IEEE transactions on power delivery, vol/issue: 32(2), 2017.

[20] J. S. Lai and P. Venkatesh, "A shunt-connected phase-shift transformer for shipboard harmonics eliminating rectifiers," Energy, Power and Transportation Electrification (ACEPT), Asian Conference on Oct. 2016, Added to IEEE Xplore, 2017.

[21] D. A. Paice, "Multipulse Methods and Transformers in Power Electronics Converter Harmonics Multipulse Methods for Clean Power," New York, USA, IEEE Press, pp. 25-37, 1995.

[22] Marian P., et al., "Control in Power Electronics," USA, Elsevier Science, pp. 472, 2002.

[23] S. Furuki and G. Ishizuka, "Transformer-Rectifiers Package (S-Former) for Aluminum Smelters," Fuji Electric Review, vol/issue: 48(2), 2008.

\section{BIOGRAPHIES OF AUTHORS}
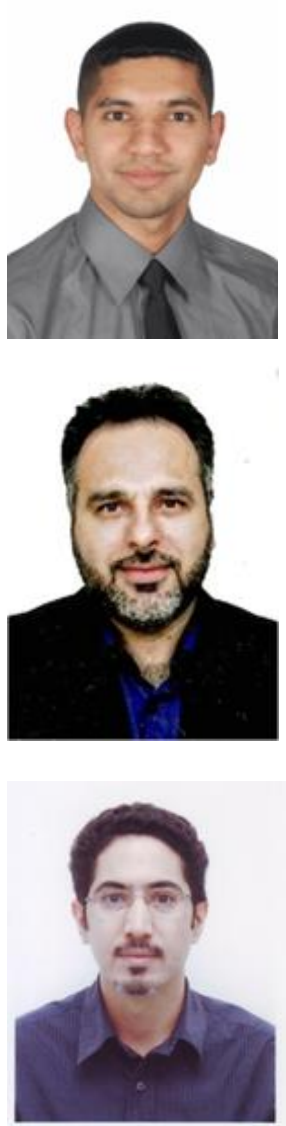

Mahmood Al-Mahari received his B.Sc. and M.Sc. degrees in Electrical Engineering from the University of Bahrain in 2010 and 2018, respectively. Currently, he is with Aluminum Bahrain power department working as maintenance electrical engineer responsible for Potlines Rectiformers maintenance and associated systems and services.

Dr. S. Ali Al-Mawsawi received his B.Sc. degree (F. Hons) in Electrical and Electronics Engineering from University of Bahrain in 1988. He received the M.Sc. degree in Power Electronics from University of Bradford in 1990 and Ph.D. degree in Power Electronics from Imperial College, University of London, UK, in 1995. Currently he is an associate professor with the University of Bahrain. Dr. Al-Mawsawi published number of papers in a highly reputed refereed international journals and conferences on Power Electronics Applications and FACTS devices. His research interest includes Power Electronics, FACTS Devices and Control Applications.

Dr. Fadhel A. Albasri received the B.Sc. and M.Sc. degrees in Electrical Engineering from University of Bahrain, Bahrain, and Ph.D. degree in the same field from University of Western Ontario, Canada, in 1992, 1997 and 2007, respectively. He worked in Ministry of Electricity and Water, Bahrain, as an electrical engineer from 1993 to 1994. In 1994, he joined the University of Bahrain as teaching and research assistant and currently an assistant professor in the department of electrical engineering. His research interest is power systems protection, power systems analysis and FACTS-device. 